\title{
Parametric Study with Simulation of Transport Phenomenon of a Solid Oxide Fuel Cell
}

\author{
A Laouar*, D Omeiri \\ University of August 20, 1955-Skikda and Laboratory of \\ Physico-Chemistry of Surfaces and Interfaces, Algeria
}

\begin{abstract}
The solid oxide fuel cells (SOFC) have the potential to become one of the efficient and cost-effective direct management systems for converting a wide variety of fuels into electricity.

In this study, we developed a three-dimensional model with a single phase of a solid oxide fuel cell (SOFC) planar fueled with hydrogen to improve the fundamental understanding of transport phenomena and performance in the SOFC.

The simulations were carried out using COMSOL Multiphysics software (version 5.4) based on the finite element method for solving the continuity equation (mass transport), the conservation equation (transport of the moment of transport). gas, ordinary diffusion transport of chemical species, heat transfer, charge transport), a parametric study was done to examine the effect of certain parameters such as the operating pressure, the temperature and porosity the porosity of the electrodes) the gas diffusion layer (GDL) on the performance of the SOFC stack for boundary conditions.
\end{abstract}

\section{INTRODUCTION}

With the oil conflict, oil price issues and the need to reduce greenhouse gas emissions interest in fuel cells growing and manufacturers to find new solutions for the future. Fuel cells are electrochemical devices that convert the chemical energy of a fuel directly into electrical energy and heat. The term fuel cell generally refers to a stack of different fuel cells, or repeaters, arranged in series to achieve power capabilities.

A fuel cell does not discharge itself and does not require charging, but works as long as fuel and oxidant are provided so offer a unique advantages, in terms of energy efficiency is high; near-zero-emissions with clean hydrogen that can help to significantly reduce emissions of greenhouse gas that is to say, that produced from water and renewable energy, mechanical simplicity, however, they have certain weaknesses the high cost of manufacture, the lifetime, their weight and their volume [1].

Moreover, they can be used in a wide range of applications because of their flexible operation, that is, they can be used alone or in hybrid systems in portable transport and applications.

Fuel cells are therefore also seen around the world, a key technology to meet the energy challenges of the 21 st century, as evidenced by the growing investments in this area because of its potential market competitiveness, oxide fuel cells solid (SOFC) have recently appeared and have electrical efficiency and relatively low cost compared to other types of fuel cells

*Corresponding Author: laouaramina@ymail.com 
such as alkaline fuel cell (AFC), proton exchange membrane fuel cell (PEM), SOFCs are most effective (in terms of electricity output in fuel consumption) or current yields around 47\% [1$2]$. The high operating temperature of SOFC produces high-quality heat that can be used for cogeneration or for combined cycle applications, increasing efficiency up to $70 \%$ [3].

To analyze the performance of the cell SOFC, we have studied a stationary threedimensional model of a single-phase isothermal and counter flow gas. The modeling is based on computational fluid dynamics (CFD) has been implemented in COMSOL Multiphysics software (Version 5.4).

We have examined the effect of certain parameters such as three different temperatures $\left(800{ }^{\circ} \mathrm{C}, 900{ }^{\circ} \mathrm{C}\right.$ and $1000{ }^{\circ} \mathrm{C}$ ), the operating pressures (1 atm, 2atm, 3atm), and the porosity of the electrodes for the gas diffusion layer $\operatorname{GDL}(0.4,0.6,0.8)$. A parametric study was carried out. As the result, we found out that the key parameters of work efficiency for improving the SOFC stack performance.

This document is organized as follows: Section 2 describes the SOFC model and geometric conception, a complete mathematical model to better characterize physical behavior is in section 3, in section 4 the numerical description and results of the simulation and discussion is presented in section 5. Finally, the main conclusions of the document are drawn in the last section.

\section{MODEL DESCRIPTION}

The solid oxide fuel cells are based on the concept of an oxygen-ion conducting electrolyte, through which oxide ions migrate from the cathode side (Lanthanum strontium cobalt ferrite) to the anode side (nickel oxide) [4]. Figure 1 shows the operating principle of a solid oxide fuel cell.

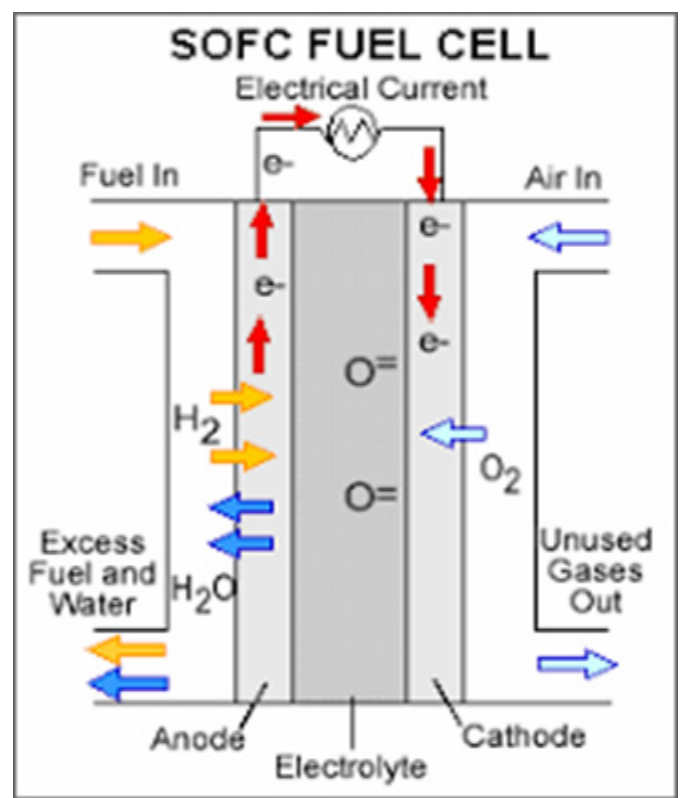

Figure 1. Operating principle description of a SOFC fuel cell. [4] 
The electrolyte is like a membrane based on zirconia (Yttria stabilized zirconia) which allows protons to pass without electrons, the anode and the cathode allow the electrons to circulate in and out of the fuel cell to start the reaction, the hydrogen is directed into the anode or the protons and the electrons separate the electrons come out of the electrode constituting the negative pole of the pile (the anode) this half pile is the seat of an oxidation[11]:

$$
\mathrm{H}_{2} \rightarrow 2 \mathrm{H}^{+}+2 \mathrm{é}
$$

The electrons enter through the electrode constituting the positive pole of the battery (the cathode) this half battery is the seat of a reduction:

$$
1 / 2 \mathrm{O}_{2}+2 \mathrm{H}^{+}+2 \mathrm{é} \rightarrow \mathrm{H}_{2} \mathrm{O}
$$

The overall electrochemical reaction in the SOFC fuel cell is as follows:

$$
\mathrm{H}_{2}+1 / 2 \mathrm{O}_{2} \rightarrow \mathrm{H}_{2} \mathrm{O}+\text { énergie électrique + chaleur }
$$

The modeling geometry is based on a three-dimensional planar SOFC of a single cell that is shown in Figure 2 for the counter-flow configuration. The geometric parameters of this model are given in the following table 1 .



Figure 2. model geometry studied in 3D

Table 1. Geometric parameters of the simulation domain.

\begin{tabular}{lll}
\hline Parameter & Value & Unit \\
\hline Width of the gas flow channel & 0.5 & $\mathrm{~mm}$ \\
Rib width & 0.5 & $\mathrm{~mm}$ \\
Gas diffusion electrode thickness & 0.1 & $\mathrm{~mm}$ \\
Electrolyte thickness & 0.1 & $\mathrm{~mm}$ \\
Height of gas flow channel & 0.5 & $\mathrm{~mm}$ \\
Length of the flow channel & 10 & $\mathrm{~mm}$ \\
\hline
\end{tabular}




\section{MATHEMATICAL MODEL}

The distribution of the current density in the SOFC model is includes the complete coupling between mass balances at the anode and the cathode, the momentum in the gas channels, the balance of the ionic current carried by the oxide ion, and an electronic current balance To deepen these aspects and fundamental understanding of transport phenomena (momentum transport, heat transport, mass transport) and performance in the SOFC it is necessary to resort to mathematical model that describes the performance of such fuel cells [1-5-6].

The different physico-chemical and electrochemical phenomena of transfer are:

- Transport of chemical species (mass transfer) in the supply channels.

- Proton transport across the membrane.

- Transport of electrons in the electrodes and the current collectors.

- Diffusion of species in the electrodes.

- Electrochemical reaction

The mass transport in electrodes and fuel and air channels, which is influenced by electrochemical reactions is described by the Maxwell-Stefan diffusion and convection systems, which is defined as follows [6]:

$$
\nabla\left(-\rho . w_{i} \sum \bar{D}_{i j} \cdot \nabla x_{j}+(x j-w j) \cdot \frac{\nabla p}{p} \cdot \mathrm{u}-D_{i}^{T} \cdot \frac{\nabla T}{T}\right)+\rho \cdot \text { u. } \nabla w j=S_{i}
$$

with: $\mathrm{xj}=\frac{\mathrm{wj}}{\mathrm{Mj}} \cdot \mathrm{M} \quad ; \quad \sum_{i=1}^{n} w_{i}=1 \quad ; \quad M_{i j}=\frac{2}{\frac{1}{M_{i}+\frac{1}{M_{j}}}}$

Where:

$w=$ the mass fraction

$\bar{D}_{i j}=$ the binary diffusion coefficient represents the component $i j$ of the multicomponent Fick's diffusivity, which is calculated from the Maxwell-Stefan diffusivities $D_{i j}\left(\mathrm{~m}^{2} / \mathrm{s}\right)$

$D_{i}^{T}=$ the thermal diffusion coefficient

$\mathrm{x}=$ the mole fraction of the species

$S_{i}=$ the species source term i $\left(\mathrm{kg} / \mathrm{m}^{3} . s\right)$.

In this case, $S_{i}$ is equal to zero because the electrochemical reactions are supposed to take place at the interfaces between the electrolyte and the electrodes. So, they are defined as an interface condition and not as a source term. The diffusion coefficient in the electrodes is:

$$
D_{i j}, \text { por }=\frac{D_{i j} \cdot \varepsilon_{p}}{t}
$$

Where $t$ is the tortuosity.

In the gaseous diffusion layer, the binary diffusion coefficient $D_{i j}$ must be corrected to take into account the porosity $\varepsilon$ using the Bruggemann correction [7]: 


$$
D_{i j}^{e f f}=D_{i j} \cdot \varepsilon^{1.5}
$$

The equations governing a transport phenomenon governing these complex transfer processes at the core of SOFC including conservation equations are:

Equation of continuity:

$$
\nabla(\varepsilon \rho \vec{u})=0
$$

Momentum equation:

$$
\nabla(\varepsilon \rho \vec{u} \vec{u})=-\varepsilon \nabla P+\nabla(\varepsilon \mu \nabla \vec{u})+S_{u}
$$

Mass transfer equation:

$$
\nabla\left(\varepsilon \vec{u} w_{i}\right)=\nabla\left(D_{i j} \nabla w_{i}\right)+S_{i}
$$

Charge conservation equation:

$$
\nabla(\sigma . \nabla \phi)+S_{\phi}=0
$$

The equations concern the electrochemical reaction are given by the Butler-Volmer equation [8-9]:

At the anode:

$$
i_{a}=\left(a i_{0}^{r e f}\right)_{a}\left(\frac{c_{H 2}}{c_{H 2, \text { ref }}}\right)^{\beta a}\left[\exp \left(\frac{\alpha_{a}^{-} F}{R T} \eta_{a}\right)-\exp \left(\frac{\alpha_{c}^{-} F}{R T} \eta_{a}\right)\right]
$$

At the cathode:

$$
i_{c}=\left(a i_{0}^{r e f}\right)_{c}\left(\frac{c_{O 2}}{c_{O 2, r e f}}\right)^{\beta_{c}}\left[\exp \left(\frac{\alpha_{a}^{+} F}{R T} \eta_{c}\right)-\exp \left(\frac{\alpha_{c}^{+} F}{R T} \eta_{c}\right)\right]
$$

The activation overvoltage $\eta$ of an electrochemical reaction is defined by [10]:

At the anode:

$$
\eta_{a}=\phi_{e}-\phi_{p}
$$

At the cathode: 


$$
\eta_{c}=\phi_{e}-\phi_{p}-E_{0}
$$

Where $E_{0}$ is the open circuit thermodynamic potential of the reaction. Is expressed from the Nernst equation [10]:

$$
E_{0}=1.23-0.9 \times 10^{-3}(T-298)+2.3 \frac{R T}{4 F} \log \left(p_{H 2}^{2} \cdot p_{O 2}\right)
$$

\section{NUMERICAL METHOD}

The set of coupled governance equations has been implemented and solved in the commercial software COMSOL based on the finite element method for partial resolution. For the research presented here, the 'Batteries and Fuel Cells' module was used by loading the SOFC-unit -cell module. which offers the user the possibility to build models of electrodes and electrolytes in detail thus gives an easy interface for the modeling aspect, which is designed precisely to treat Multiphysics problems, the software proposes additional modules specific to every field of physics. Calculation domains are created in the software [9].

The computational grid used for the main modeling domain is illustrated in Figure 3. That represents the studied model after meshing in a three-dimensional structure attached with Figure 4 which presents the geometry mesh in two dimensions according to the plane $x y$ (in terms of width and height).

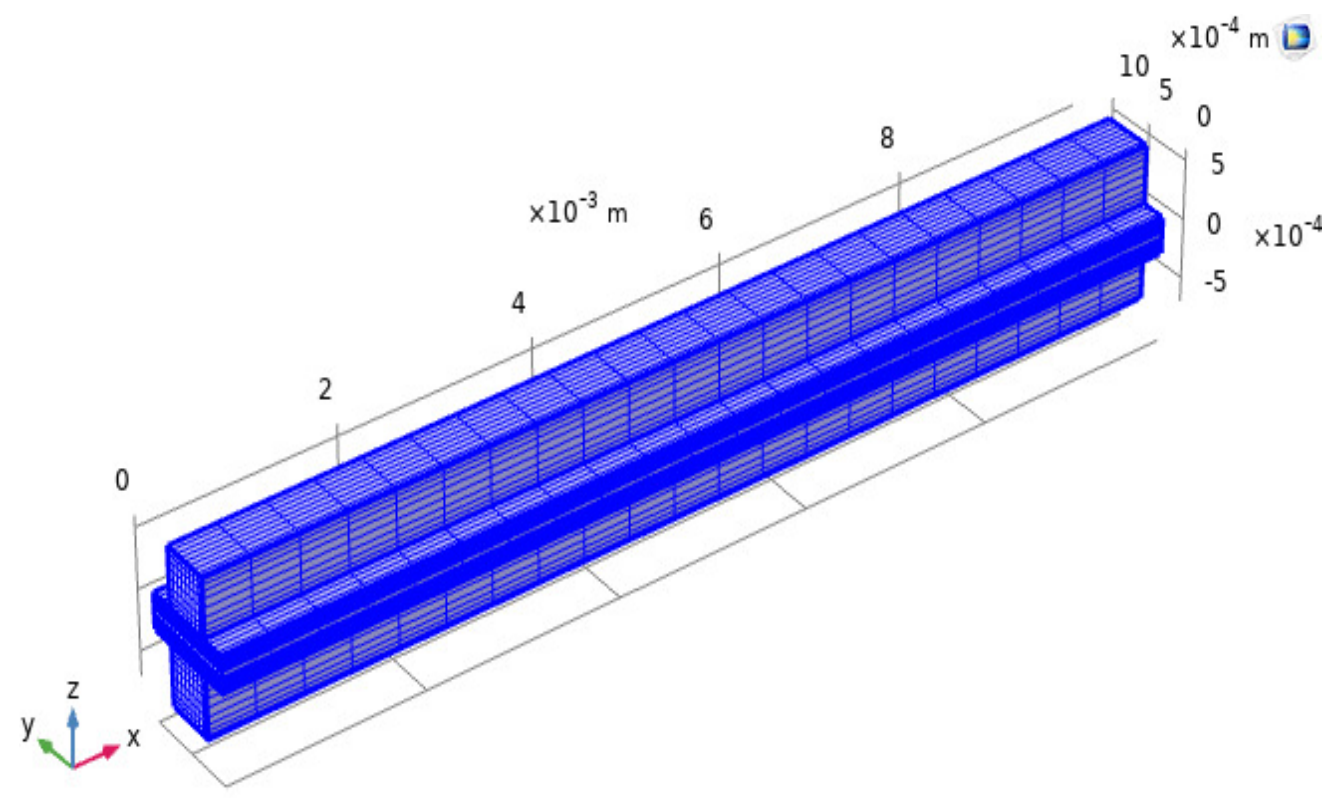

Figure 3. The mesh of the 3D model. 


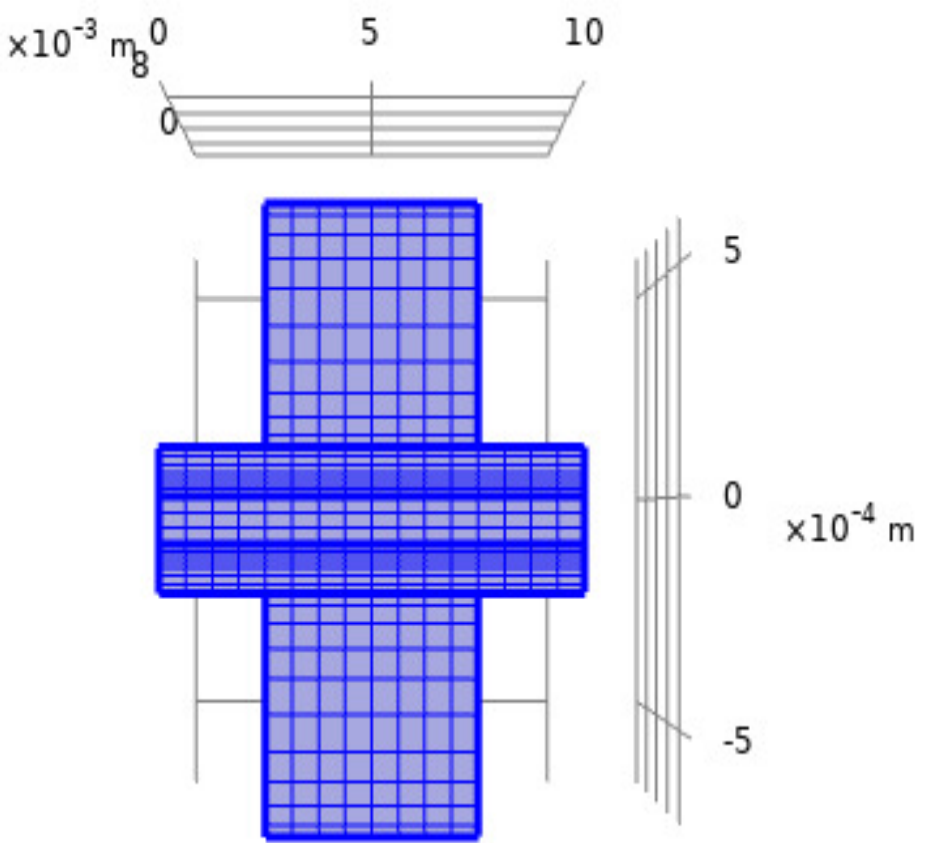

Figure 4. The mesh according to the XY plane.

\section{RESULTS AND DISCUSSION}

The model predicts the polarization curves (SOFC voltage vs current density) and power (power density vs. current density) In order to evaluate the performance of the SOFC, we examine the effect of various parameters such as the porosity of GDL, the operating pressure and temperature of the cell SOFC, a parametric study was conducted.

The temperature is changed to $800{ }^{\circ} \mathrm{C}, 900{ }^{\circ} \mathrm{C}$ and $1000{ }^{\circ} \mathrm{C}$ and we obtained the characteristic curves for the counter-flow gas as shown in Figures 5 and 6 . The figures illustrate the characteristic polarization and power, the voltage gradually decreases with the increase of the current density. Moreover, with the increase of the temperature.

The figures 7 and 8 respectively present the power curves for different pressure values and the Polarization curves for different pressure values, where the figures show the shows the variation of the SOFC potential and power as a function of the current density for different pressure values ( $p=1,2,3 \mathrm{~atm}$.). It is shown that the effect of the pressure on the SOFC performance is important due to their influence on several parameters such as the composition of the gases at the inlet, the exchange current density and the binary diffusion coefficient of the species in the mass transfer equation.

The porosity of the electrodes is another sensitive parameter affecting the performance of the fuel cell for the optimal performance of the fuel cell. Figures 9 and 10 illustrate the evolution of the performance of the fuel cell with different values of porosities $(\varepsilon=$ $0.4,0.6,0.8)$ of a gas electrode at a constant operating temperature of $800{ }^{\circ} \mathrm{C}$ and a pressure of $1 \mathrm{~atm}$. The reduction of the porosities of the gas distribution electrodes leads to a decrease in the performance of the fuel cell. 


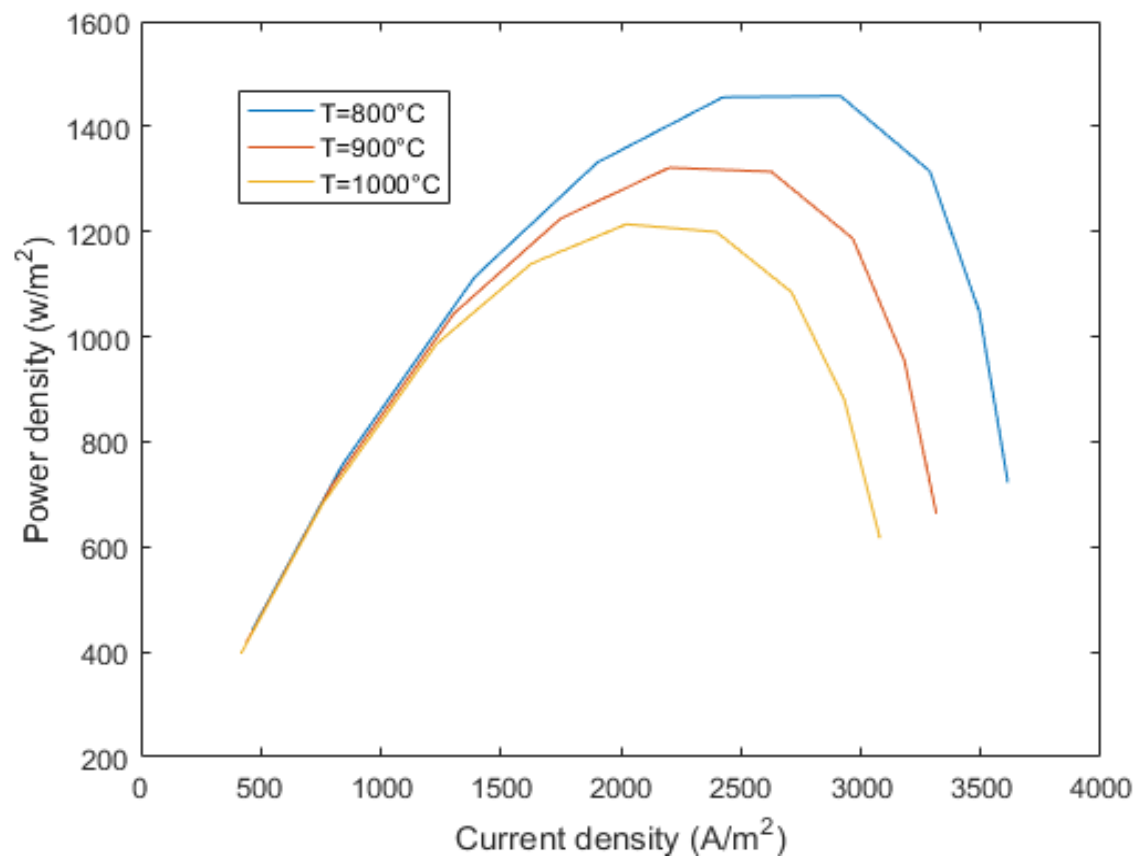

Figure 5. Polarization curves for different temperature values

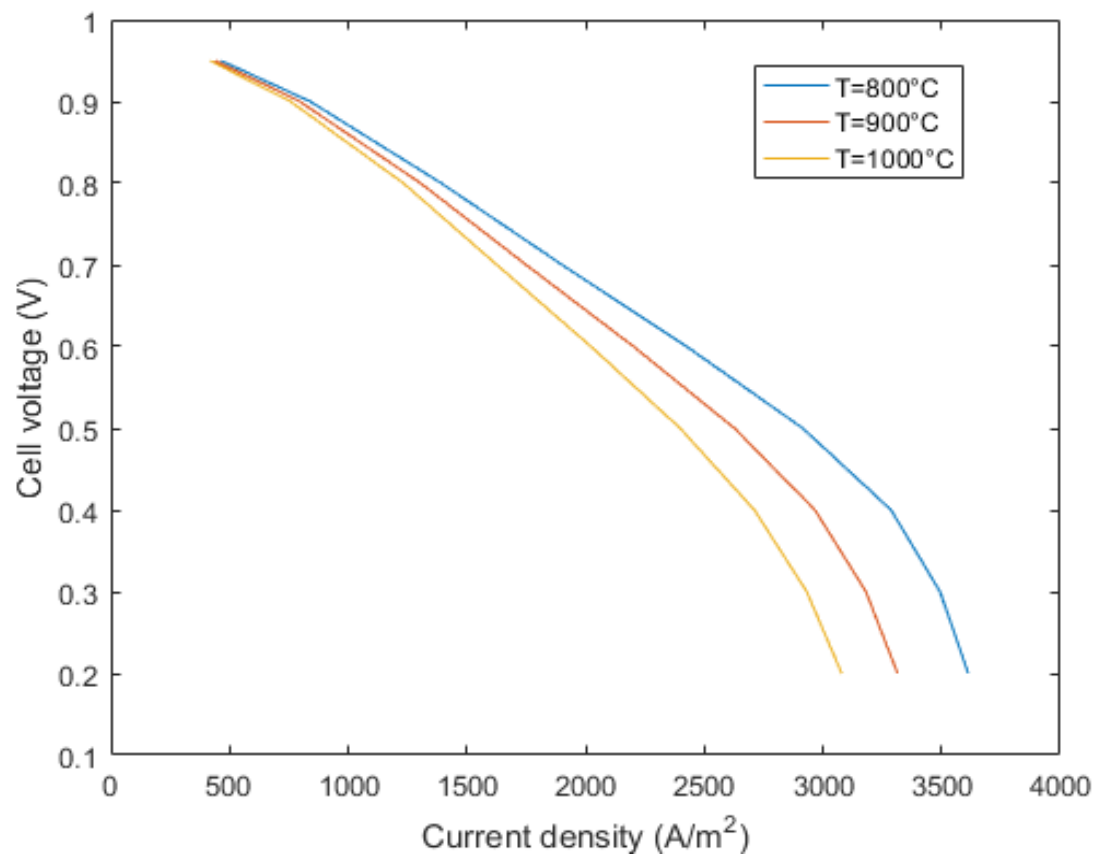

Figure 6. Power curves for different temperature values 


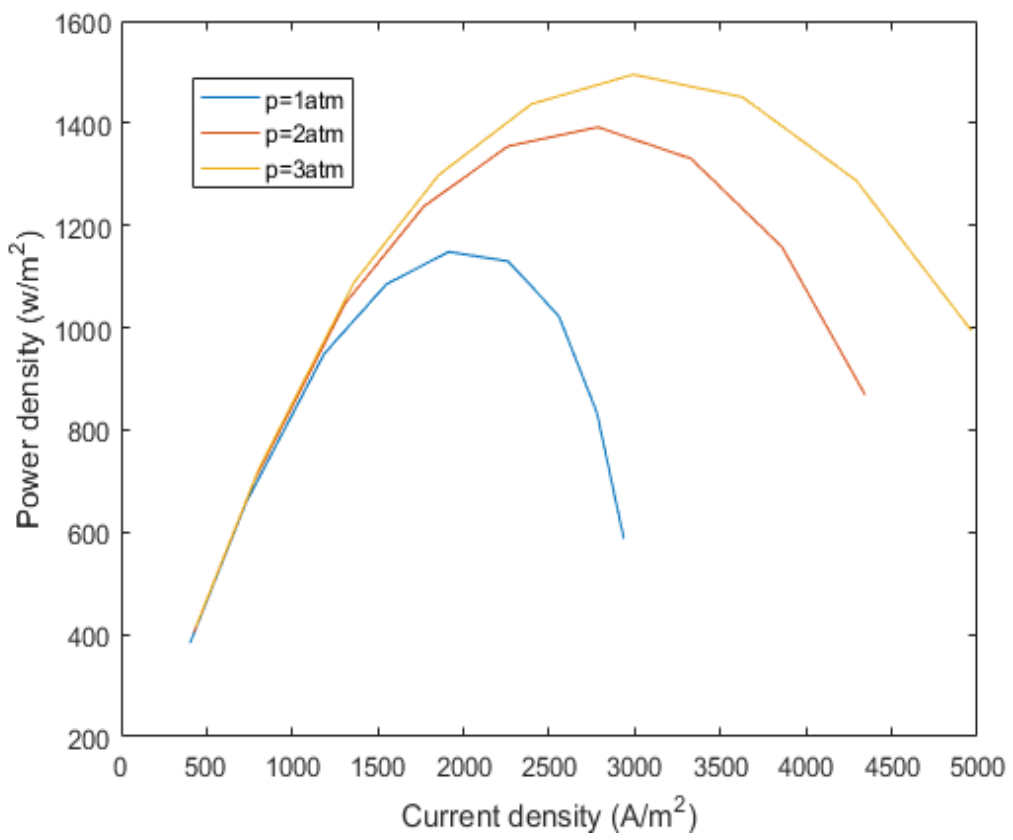

Figure 7. Power curves for different pressure values

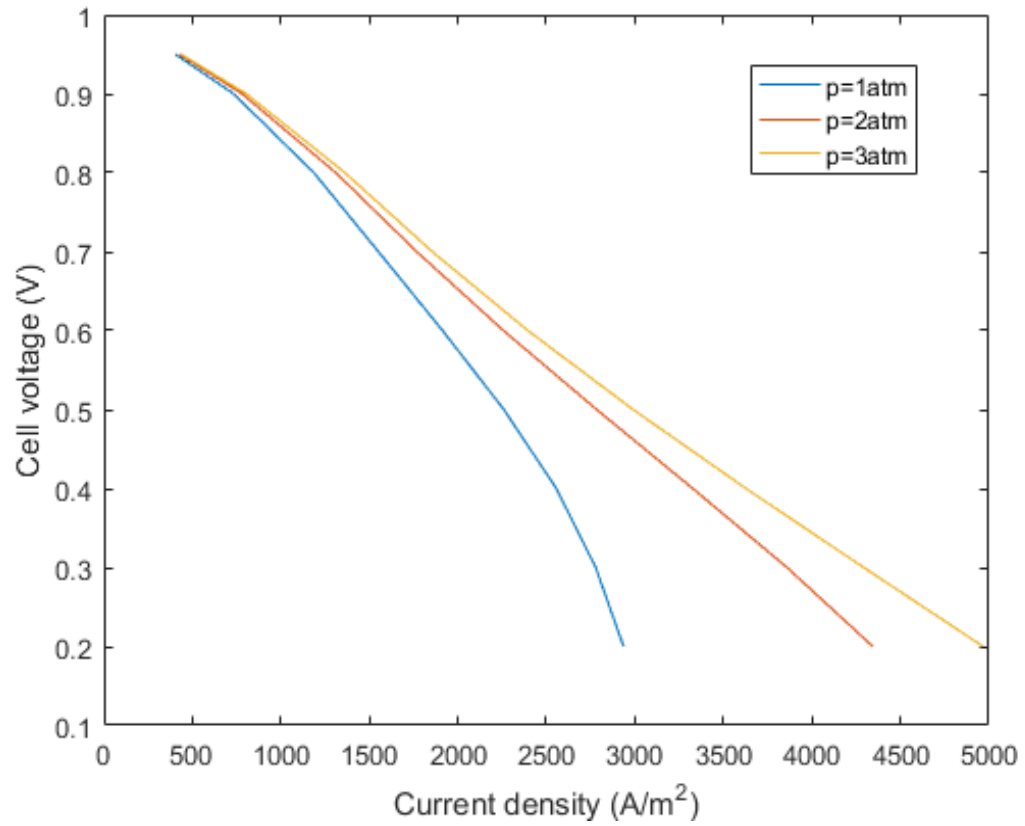

Figure 8. Polarization curves for different pressure values 


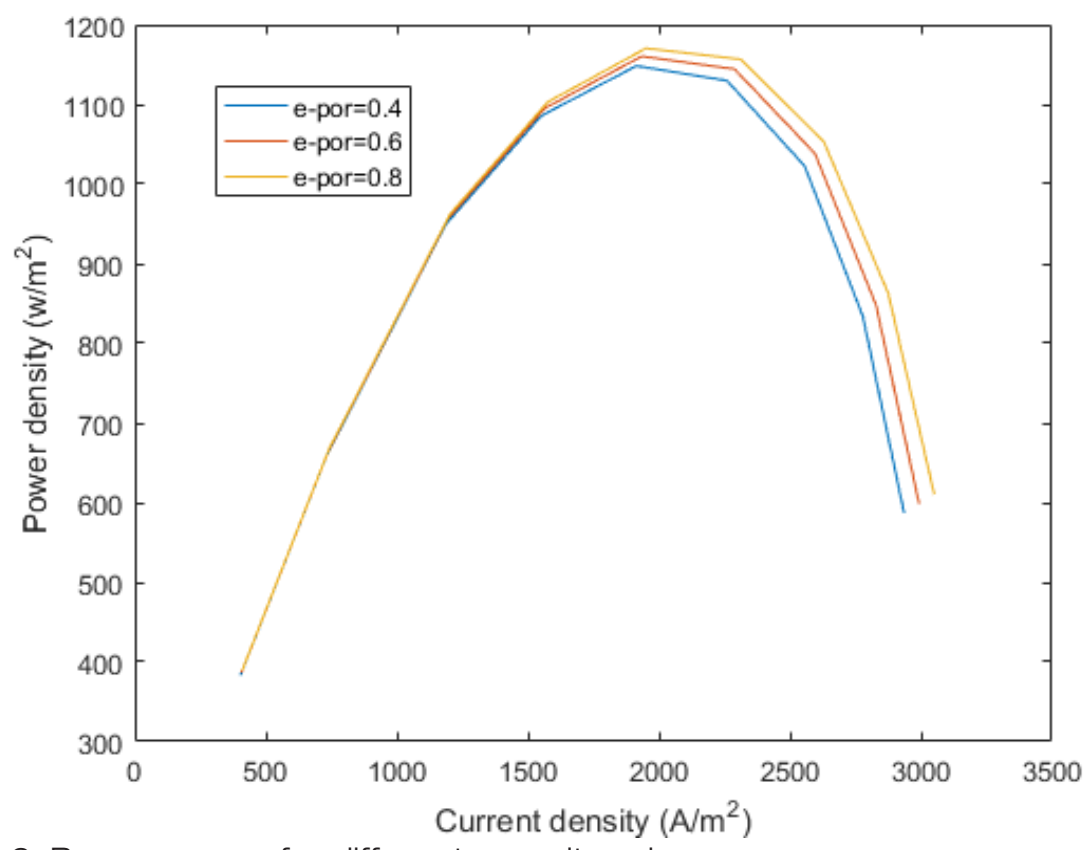

Figure 9. Power curves for different porosity values

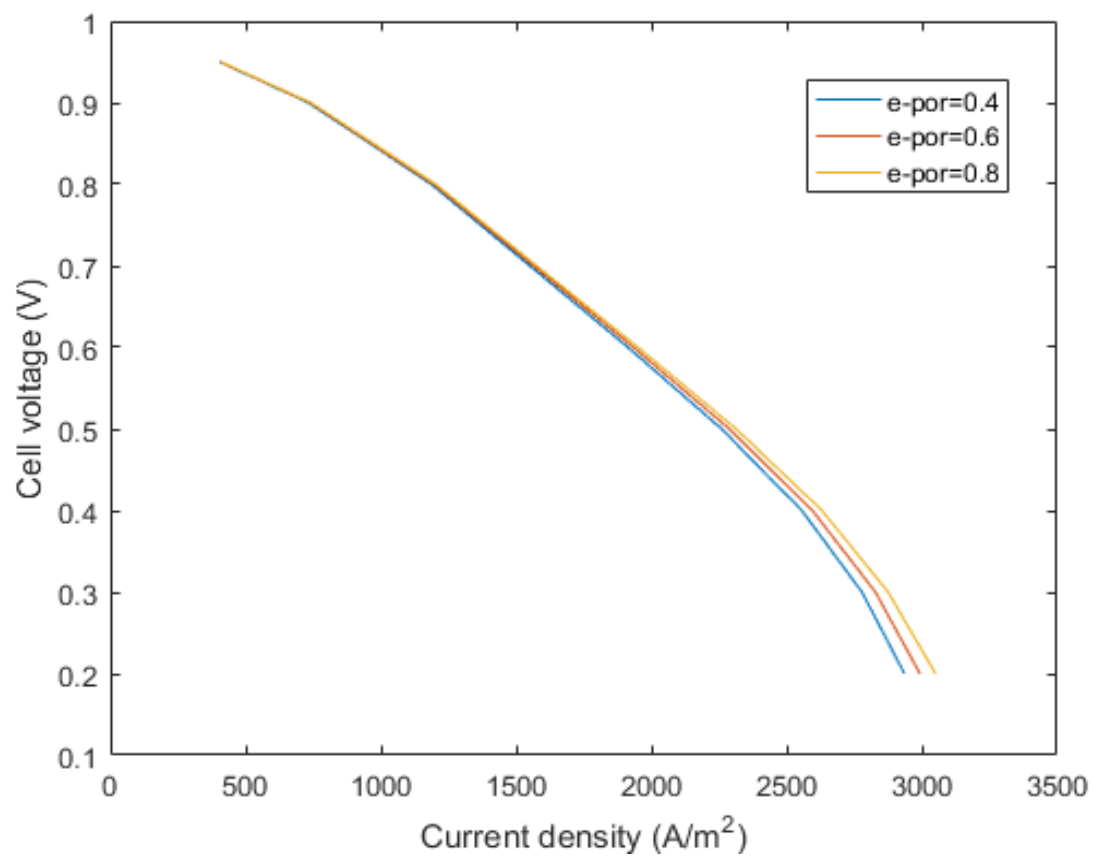

Figure 10. Polarization curves for different porosity values. 


\section{CONCLUSION}

Based on the above features, it is clear that high-temperature operation is the reason for most of the benefits of SOFC. However, high operating temperatures are also the source of the main challenges SOFC technology

it is noted that the increase of the porosity of the electrodes favors the diffusion of the reagents in the pores (place of electrochemical reaction). Therefore, the increase in the porosity of the GDL improves the performance of the SOFC but remains low compared to the influence of the operating pressure on the SOFC performance.

\section{REFERENCES}

[1] Valerio Novaresio, María García-Camprubí, Salvador Izquierdo, Pietro Asinari Norberto Fueyo,(2012), “An open-source library for the numerical modeling of mass-transfer in solid oxide fuel cells", Computer Physics Communications 183 (2012) 125-146.

[2] S.C. Singhal (2002) "Solid oxide fuel cells for stationary, mobile, and military applications" Solid State Ionics 152-153 (2002) 405- 410.

[3] Nguyen Q. Minh, (2004) "Solid oxide fuel cell technology—-features and applications", Solid State Ionics 174 (2004) 271-277

[4] E. lay (2009) "Nouveaux materiaux d'electrode de cellule SOFC", Universiteti of Joseph Furierit - Grenoble I, HAL Id: tel-00461152.

[5] Yuan J., Ren F., Sundén (2006) "Analysis of Chemically Reacting Transport Phenomena in an Anode Duct of Intermediate Temperature SOFCs" J. Fuel Cell Sci. Technol., 3, pp. 687-701.

[6] Hedvig Paradis ( 2009 ) "CFD Simulations of Transport Processes including Chemical Reactions in SOFCs", Division of Heat Transfer department of energy sciences faculty of engineering (LTH), Lund University ISRN LUTMDN/TMHP_09/5197—SE.

[7] D.M. Bernardi and M.W. Verbrugge (1992) "A Mathematical Model of the Solid Polymer Electrolyte Fuel Cell', J.Electrochem,139(9): 2477-2491.

[8] Sasanka N. Ranasinghe and Peter H. Middleton (2017) "Modelling of Single Cell Solid Oxide Fuel Cells Using COMSOL Multiphysics", IEEE International Conference on Environment and Electrical Engineering

[9] Comsol multiphysics cyclopedia," Online available: https://www.comsol.no/multiphysics.

[10] Martin Andersson, Hironori Nakajima , Tatsumi Kitahara, Akira Shimizu, Takahiro Koshiyama ,Hedvig Paradis , Jinliang Yuan , Bengt Sundén (2014) "Comparison of humidified hydrogen and partly pre-reformed natural gas as fuel for solid oxide fuel cells applying computational fluid dynamics", International Journal of Heat and Mass Transfer 77 (2014) 1008-1022.

[11] "Fuel cell today - SOFC," Online available:

http://www fuelcelltoday.com/technologies/sofc. 
